\title{
Copper-Based Nanostructured Coatings for Low-Temperature Brazing Applications
}

\author{
Benjamin Lehmert ${ }^{2}$, Jolanta Janczak-Rusch ${ }^{1, * 1}$, Giancarlo Pigozzi ${ }^{1, * 2}$, Peter Zuraw ${ }^{1,2}$, \\ Fabio La Mattina ${ }^{3}$, Lukas Wojarski ${ }^{2}$, Wolfgang Tillmann ${ }^{2}$ and Lars P. H. Jeurgens ${ }^{1}$ \\ ${ }^{1}$ Empa, Swiss Federal Laboratories for Materials Science and Technology, Laboratory for Joining Technology and Corrosion, \\ Überlandstrasse 129, 8600 Dübendorf, Switzerland \\ ${ }^{2}$ Dortmund University of Technology (TU Dortmund), Institute of Materials Engineering, Faculty of Mechanical Engineering, \\ 44227 Dortmund, Germany \\ ${ }^{3}$ Empa, Swiss Federal Laboratories for Materials Science and Technology, Reliability Science and Technology Laboratory, \\ Überlandstrasse 129, 8600 Dübendorf, Switzerland
}

\begin{abstract}
This feasibility study demonstrates the possibility to apply nanostructured filler materials for novel low-temperature brazing applications by exploiting the size-dependent melting behavior of metals and alloys when confined to the nano-scale regime. As an example, a copper-based nanostructured brazing filler is presented, which allows metal brazing of coated Ti-6Al-4V components at $750^{\circ} \mathrm{C}$, much below the bulk melting point of copper $\left(1083^{\circ} \mathrm{C}\right)$. The copper-based nanostructured brazing fillers can be produced in the form of coatings and free-standing brazing foils. The nano-confinement of $\mathrm{Cu}$ is abrogated after brazing and, consequently, the brazed joints can be operated well above their reduced brazing temperatures. [doi:10.2320/matertrans.MI201419]
\end{abstract}

(Received December 22, 2014; Accepted March 9, 2015; Published April 24, 2015)

Keywords: copper, thin films, multilayer, brazing, pre-melting, interfaces

\section{Introduction}

The maximum process temperature reached during a joining procedure is one of the most critical process parameters for brazing heat-sensitive (nano-)materials and metallic alloys. On the one hand, the maximum brazing temperature has to be high enough to melt the brazing alloy and establish a firm chemical joint. On the other hand, the brazing temperature should be low enough to prevent irreversible microstructural changes in the base material (by e.g. phase transformations, grain growth and/or partial melting) and also to reduce residual stresses in the joined assembly.

The melting point of commercial braze fillers is typically tuned by adding a melting point depressant, such as boron, phosphor, zinc, tin, indium or silicon. However, such an alloying approach for lowering the brazing temperature has strict chemical and physical limitations, as dictated by bulk thermodynamics. For example, typically only a moderate reduction of the melting temperature of the braze filler can be achieved. Moreover, the melting point depressant(s) can deteriorate the mechanical properties of the joint.

A novel strategy for lowering the brazing temperature over a wide temperature range is to exploit the known sizedependence of the melting point of metals and alloys when confined to the nanoscale regime ${ }^{1-4)}$ in combination with the intrinsically fast diffusion of atoms along free surfaces and incoherent internal interfaces in nano-sized and structured metals. ${ }^{5-10)}$ On this fundamental basis, for example, pastes with Ag nanoparticles have been developed for joining (electronic) components at temperatures as low as $300^{\circ} \mathrm{C}$ (significantly below the bulk melting temperature of $\mathrm{Ag}$ of $\left.962^{\circ} \mathrm{C}\right) .{ }^{9,10)}$ However, the use of metal nanoparticles can have

\footnotetext{
${ }^{* 1}$ Corresponding author, E-mail: jolanta.janczak@empa.ch

${ }^{*}$ Present address: Zimmer GmbH: Sulzerallee 8: CH-8404 Winterthur, Switzerland
}

significant disadvantages in industrial practice, for example, due to handling and safety issues, agglomeration, oxidation (ageing) and sintering during heating.

In the present paper, a novel concept for low-temperature joining, using a nanostructured brazing filler in a multilayer configuration, is introduced and described exemplary for a nano- $\mathrm{Cu}$ brazing filler, as applied to join a Ti-6Al-4V alloy (TAV) well below the bulk melting temperature of $\mathrm{Cu}$. To this end, alternating nanolayers of pure copper and aluminiumnitride were deposited on Ti-6Al-4V plates. The coated titanium alloy components were successfully brazed at $750^{\circ} \mathrm{C}$, well below the melting temperature of the bulk $\mathrm{Cu}$ brazing filler metal $\left(1083^{\circ} \mathrm{C}\right)$.

\section{Experimental Procedure}

\subsection{Base materials and coating deposition}

Ti-6Al-4V plates with dimensions of $10 \times 10 \times 2.5 \mathrm{~mm}^{3}$ were produced. Prior to the deposition process, the plates were grinded and polished with a diamond paste (down to a grain size of $0.25 \mu \mathrm{m}$ ). Next a $\mathrm{Cu} / \mathrm{AlN}$ nano-multilayered (NML) coating with a total thickness of $4 \mu \mathrm{m}$ was deposited on each Ti-6Al-4V plate (substrate) by conventional magnetron sputtering (see also Ref. 6)). The $4 \mu \mathrm{m}$ thick coating was constituted of 200 repetitions of a $10 \mathrm{~nm}$ thick AlN and a $10 \mathrm{~nm}$ thick $\mathrm{Cu}$ nanolayer plus a $10 \mathrm{~nm}$ thick AlN top layer, as schematically shown in Fig. 1. The sandwiched $\mathrm{Cu}$ nanolayers act as a confined brazing filler metal, whereas the intercalated AIN nanolayers serve as a chemically inert diffusion barrier to confine the alloy to the nanoscale up to its reduced melting point.

The alternating $\mathrm{Cu}$ and $\mathrm{AlN}$ nanolayers were deposited in one run using an industrial magnetron sputter device (CC $800 / \mathrm{ml}$ sinox, CemeCon, Germany). The $\mathrm{Cu}$ layers were sputtered from a pure element target $(99.9 \% \mathrm{Cu})$, applying a power of $1 \mathrm{~kW}$. The AlN layers were produced by reactive sputtering from a pure $\mathrm{Al}$ target in an $\mathrm{Ar} / \mathrm{N}_{2}$ atmosphere also 


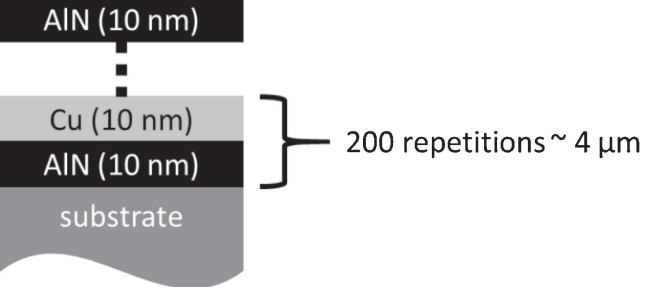

Fig. 1 Schematic image of a deposited $\mathrm{Cu} / \mathrm{AlN}$ nano-multilayer.

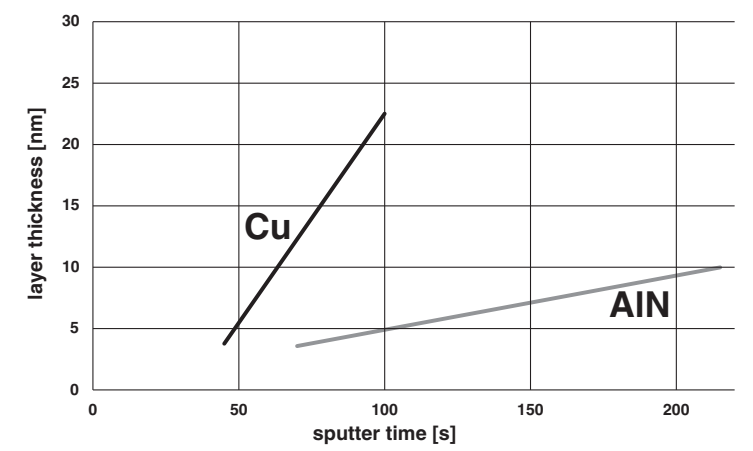

Fig. 2 Layer thicknesses of $\mathrm{Cu}$ and $\mathrm{AlN}$ after various deposition times, as obtained from spectroscopic ellipsometry.

at $1 \mathrm{~kW}$. Both targets were bonded to a water-cooled backing plate. The coating process was conducted in a vacuum $\left(<4 \times 10^{-4} \mathrm{mbar}\right)$, using argon and krypton as plasma gases, with a substrate temperature not exceeding $70^{\circ} \mathrm{C}$. Before each deposition, the substrates were ultrasonically cleaned prior to further investigations and experiments.

The deposition rates of $\mathrm{Cu}$ and $\mathrm{AlN}$ were calibrated by sputter-deposition of either $\mathrm{Cu}$ or AlN on a silicon wafer for three different deposition times and a subsequent determination of the individual layer thicknesses by spectroscopic ellipsometry (using a M $2000 \mathrm{~V}$ ellipsometer from J.A. Woollam Co., Inc.): see Fig. 2. This resulted in deposition times of $200 \mathrm{~s}$ and $70 \mathrm{~s}$ for the deposition of a $10 \mathrm{~nm}$ thick $\mathrm{AlN}$ and a $10 \mathrm{~nm}$ thick $\mathrm{Cu}$ layer, respectively.

\subsection{Annealing experiments}

Coated TAV specimens were covered with a $1 \mathrm{~mm}$ thick ceramic plate, while keeping a central gap of approximately $1 \mathrm{~mm}$ between the ceramic plate and the specimen's surface by application of $1 \mathrm{~mm}$ thick ceramic spacers. Next, a $3 \mathrm{~mm}$ thick titanium plate was placed on top and the entire assembly was introduced into a Ti jig. A pressure of $50 \mathrm{MPa}$ was evenly applied on the assembly by tightening the screw, located on top of the jig. To protect the loaded jig from contamination during brazing, the jig was enclosed in a Sen/ Pak heat treating container of high-chromium stainless steel (supplied by Sentry, USA). The sealed jig was placed in an argon shielded gas tube (Nabertherm oven using Ar purity 6.0) and heated up to $650^{\circ} \mathrm{C}$ with a heating rate of $20^{\circ} \mathrm{C} / \mathrm{min}$. This temperature was kept constant for $15 \mathrm{~min}$ to ensure a homogeneous temperature field. Next, the temperature was raised to $750^{\circ} \mathrm{C}$ with $10^{\circ} \mathrm{C} / \mathrm{min}$, followed by an isothermally annealing step at $750^{\circ} \mathrm{C}$ for $30 \mathrm{~min}$. Then the heating source was switched off, allowing the sample to freely cool down to room temperature in the furnace. It is emphasized that the conditions for the annealing experiments are analogous to the
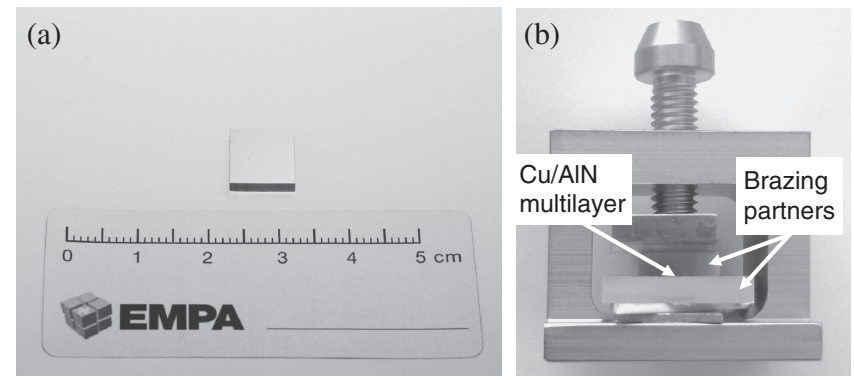

Fig. 3 Photographs of (a) a Ti-6Al-4V plate coated with a $4 \mu \mathrm{m}$ thick $\mathrm{Cu} /$ AIN multilayer and (b) a loaded Ti jig in a "ready to braze" state.

ones used for the subsequent brazing experiments (see Sec. 2.3).

\subsection{Brazing experiments}

To demonstrate the feasibility of the concept, exemplary brazing experiments of two NML-coated Ti-6Al-4V plates were performed at a brazing temperature of $750^{\circ} \mathrm{C}$ for $30 \mathrm{~min}$ (analogous to the annealing experiments described in Sec. 2.2). To this end, two NML-coated TAV pieces were put together at their (coated) front sides. Next the TAV assembly was covered on each side, first with a $1 \mathrm{~mm}$ thick ceramic plate (to avoid a reaction between the Ti jig and the specimen) and then with a 1 to $3 \mathrm{~mm}$ thick titanium plate (to ensure a uniform distribution of the applied pressure). The resulting multi-component assembly was placed into a titanium jig, applying a pressure of about $50 \mathrm{MPa}$. Photographs of a Ti-6Al-4V plate coated with a $4 \mu \mathrm{m}$ thick $\mathrm{Cu} /$ AIN multilayer and of a loaded Ti jig with the specimens in a "ready to braze" state are shown in Figs. 3(a) and (b), respectively. Prior to brazing (according to the procedure described in Sec. 2.2), the loaded jig was enclosed in a Sen/ Pak heat-treating container of high-chromium stainless steel (supplied by Sentry, USA).

\subsection{Characterisation of the nanomultilayers}

The as-deposited and annealed NML microstructures were investigated by a combinatorial approach using Scanning Electron Microscopy (FEI NovaNano SEM 230), Energy Dispersive X-ray (EDX), X-ray Diffraction (XRD) and a He Focused Ion Beam (He-FIB). The high resolution He-FIB images were taken by detecting the secondary electrons, which were emitted by scanning the cross-sectional surfaces with a focused He-ion beam, operated with a beam current of $0.5 \mathrm{pA}$ at $30 \mathrm{kV}$.

The melting temperature of the confined $\mathrm{Cu}$ nanolayers in the $\mathrm{Cu} / \mathrm{AlN}$ coatings was determined by means of differential scanning calorimetry (DSC). To this end, a $3 \mathrm{~mm} \times 3 \mathrm{~mm}$ specimen was cut out from the $10 \mathrm{~mm} \times 10 \mathrm{~mm}$ coated TAV substrate plate with a diamond-wire and adapted to fit into the crucible of the DSC device. To reduce the contribution of the thick substrate to the recorded DSC signal, the TAV substrate was partially removed (thinned) by grinding the backside of the specimen with $\mathrm{SiC}$ grinding paper. Additionally, a TAV reference specimen without NMLs was measured by DSC to record the substrate response. The coated and uncoated TAV specimens were placed into the DSC and heated up to $1100^{\circ} \mathrm{C}$ with a heating rate of $10 \mathrm{~K} / \mathrm{min}$. 


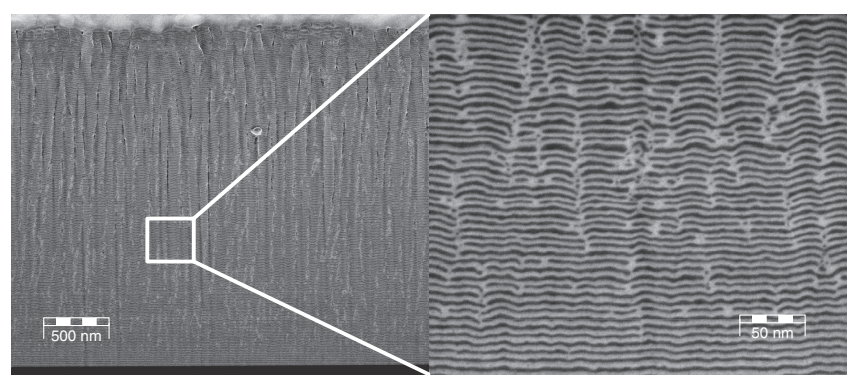

Fig. 4 Structure of the $\mathrm{Cu} / \mathrm{AlN}$ NML coating as resolved by He-Ion microscopy.

\section{Results and Discussions}

\subsection{As-deposited Cu/AIN NML microstructure}

Figure 4 shows a cross-section micrograph of the asdeposited $\mathrm{Cu} / \mathrm{AlN}$ NML coating, as imaged by a He-Ion microscope. The alternating $\mathrm{Cu}$ and $\mathrm{AlN}$ nanolayers are clearly resolved. The individual layer thicknesses are nearly constant across the coating thickness. However, defects occur in the AlN barrier layers, which originate from the deposition process (probably due to grow stresses and a deviation from a pure layer-to-layer growth mode). This results in an increasing roughness of the layered structure from the substrate/coating interface to the coating surface. The defects in the AlN barrier layers are transferred to subsequently deposited nanolayers (see Sec. 3.3).

\subsection{Melting behavior of the Cu/AIN NML}

The DSC measurement of the coated Ti-6Al-4V specimen (as thinned from the backside to reduce the substrate contribution to the measured DSC signal; see Sec. 2.4) is shown in Fig. 5. The DSC curve evidences two endothermic peaks in the range from $450^{\circ} \mathrm{C}$ to $750^{\circ} \mathrm{C}$, indicative for a heterogeneous melting of the confined $\mathrm{Cu}$ nanolayers over a relatively broad temperature range from $450^{\circ} \mathrm{C}$ (onset of melting) to $750^{\circ} \mathrm{C}$ (melting completion). The first endothermic peak, starting at around $450^{\circ} \mathrm{C}$, is attributed to the onset of melting in the more defective surface-adjacent part of the $\mathrm{Cu} / \mathrm{AlN}$ coating (see Sec. 3.1). The second endothermic peak starting at around $620^{\circ} \mathrm{C}$, could be due to the onset of interfacial pre-melting in the less defective bottom part of the $\mathrm{Cu} / \mathrm{AlN}$ coating. However, the origin of the second endotherm could also be interpreted in a different way. Namely, the onset of interfacial pre-melting will be associated with an abrupt release of accumulated thermal stresses in the confined $\mathrm{Cu}$ interlayers, which may decelerate and countervail a continuous melting. Further heating is then required to re-activate the interfacial pre-melting, resulting in the appearance of a second endothermic peak.

SEM analysis of the surface of the annealed NML-coated specimens shows a high density of solidified droplets of $\mathrm{Cu}$ (with diameters up to $3 \mu \mathrm{m}$ ) on the coating surface, in accordance with a heterogeneous melting of the confined $\mathrm{Cu}$ nanolayers and a subsequent outflow of liquid $\mathrm{Cu}$ to the NML surface in the temperature range from $450^{\circ} \mathrm{C}$ to $750^{\circ} \mathrm{C}$ : see Fig. 6. Notably a high density of cracks in the top AlN layer were observed (on average roughly 130 cracks per $\mathrm{mm}^{2}$ ), which facilitates the outflow of a vast amounts of liquid copper during annealing.

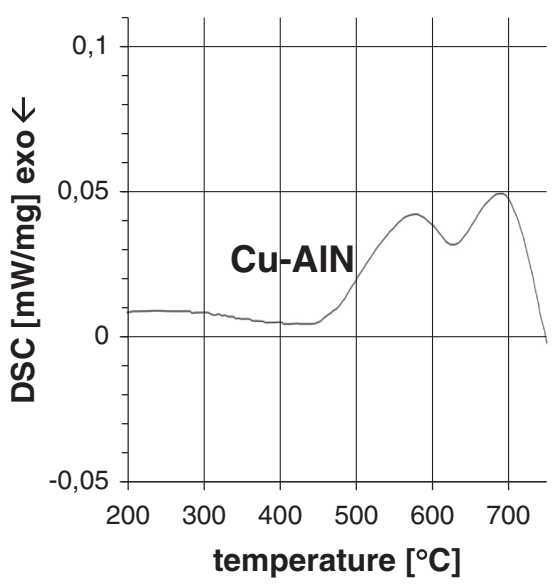

Fig. 5 DSC measurement of a NML-coated Ti-6Al-4V specimen (as thinned from the backside to reduce the substrate effect on the measured DSC signal).

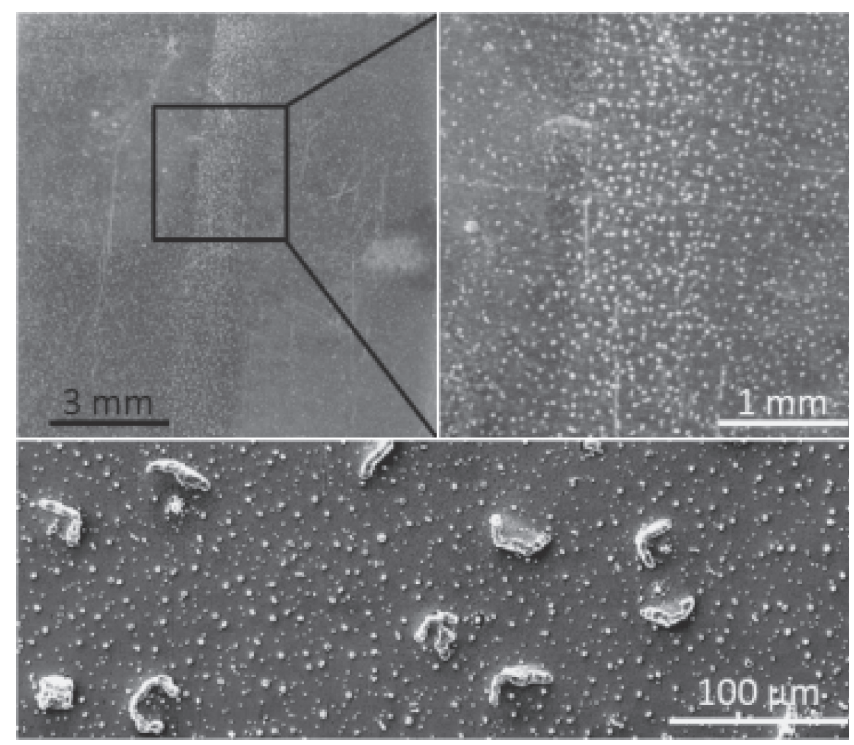

Fig. 6 Secondary electron micrograph of the surface of a NML-coated Ti$6 \mathrm{Al}-4 \mathrm{~V}$ specimen after annealing at $750^{\circ} \mathrm{C}$ for $30 \mathrm{~min}$ (see Sec. 2.2).

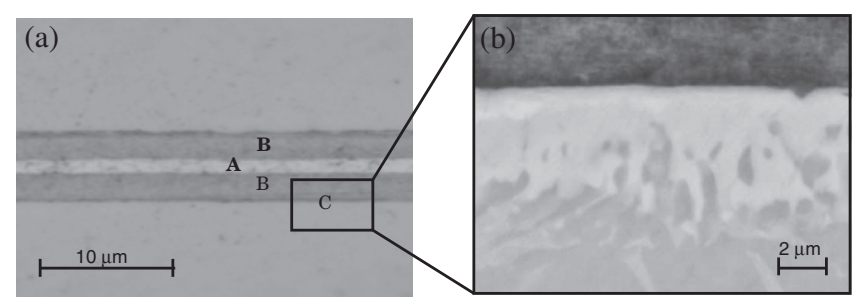

Fig. 7 Cross-sectional optical micrographs of an exemplary joint produced by brazing two NML-coated Ti-6Al-4V plates at $750^{\circ} \mathrm{C}$.

\subsection{Brazing with Cu/AIN Nanomultilayers}

Cross-sectional optical micrographs of the brazed TAV joint, produced from NML-coated TAV plates (see Sec. 2.3) are shown in Fig. 7. Evidently, a metallurgical bond between the two NML-coated Ti-6Al-4V plates could be established. In the joint area, three different microstructural zones can be identified. In the middle of the joint, a $\mathrm{Cu}$ layer (denoted as zone type A) is found, which is formed from the outflow of liquid $\mathrm{Cu}$ from the contacted coating surfaces during brazing 


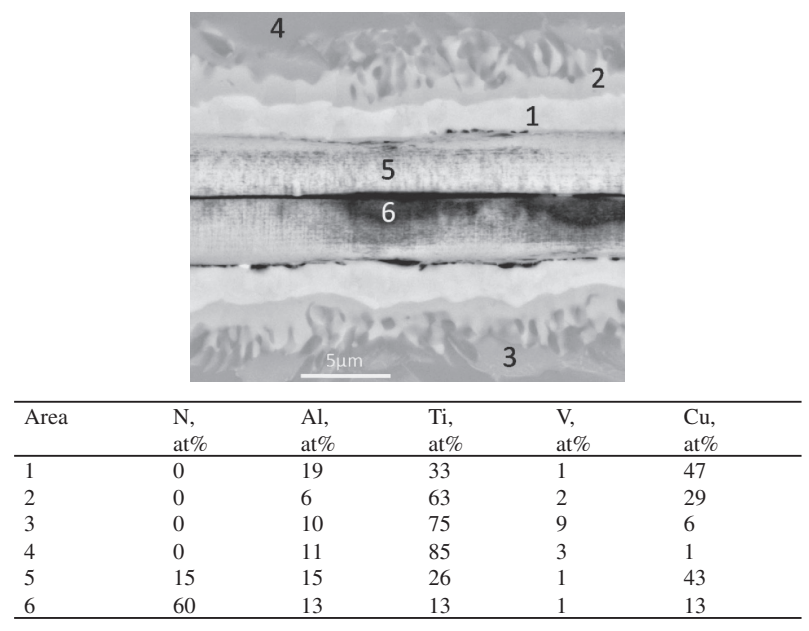

Fig. 8 Secondary electron micrograph of an exemplary joint produced by brazing two NML-coated Ti-6Al-4V plates at $750^{\circ} \mathrm{C}$. The results of the EDX analysis at the indicated positions are reported in the table.

at $750^{\circ} \mathrm{C}$. This inner $\mathrm{Cu}$ layer (A) provides a firm chemical bonding between the two joining partners. At opposite sides of the inner $\mathrm{Cu}$ layer, remnants of the "emptied" (i.e. partially sintered) AlN nanolayers with some remaining $\mathrm{Cu}$ are observed (zone B). Furthermore, a diffusion zone (C), originating from the diffusion of $\mathrm{Cu}$ into the Ti-6Al-4V alloy to form intermetallic reaction products $\left(\mathrm{Ti}_{2} \mathrm{Cu}, \mathrm{Cu}_{4} \mathrm{Ti}_{3}, \mathrm{CuTi}\right)$, is evidenced: see Fig. 8.

These preliminary brazing attempts clearly demonstrate the feasibility to join components, which are pre-coated with the $\mathrm{Cu} / \mathrm{AlN} \mathrm{NML}$, at temperatures of $750^{\circ} \mathrm{C}$, well below the bulk melting temperature of $\mathrm{Cu}\left(1083^{\circ} \mathrm{C}\right)$. The nanostructured filler concept as presented in this study exploits the non-equilibrium nature of the magnetron-sputtering deposition process to produce very defective coatings, which inherently possess a large thermodynamic driving force for interfacial pre-melting. Sputter coating defects and cracking of the AIN barrier layers during heating are desired to allow a sufficient outflow of molten metal. However, due to the heterogeneous nature of the coating microstructure, it remains challenging to assure a high reproducibility of the produced joints. Ongoing brazing experiments with other NML-coated components indicate that the outflow of molten $\mathrm{Cu}$ from the NML structure can be promoted and thereby the joint quality improved by increasing the applied pressure during brazing. Notably, the nano-confinement of $\mathrm{Cu}$ is abrogated after brazing, which results in a higher re-melting point of the joint (i.e. equal to the bulk melting point of $\mathrm{Cu}$ ), thus allowing a service temperature of the joint well above its reduced brazing temperature. Finally, it is emphasized that $\mathrm{Cu} / \mathrm{AlN}$ NMLs can also be produced in the form of freestanding brazing foils for some applications if required.

\section{Conclusions}

The present study illustrates the feasibility to apply nanostructured filler materials for novel low-temperature brazing processes by exploiting the size-dependent melting behavior of metals and alloys when confined to the nanoscale regime. Successful brazing of Ti-6Al-4V plates with pure copper was realized at a temperature as low as $750^{\circ} \mathrm{C}$ (i.e. much below the bulk melting point of copper of $1083^{\circ} \mathrm{C}$ ) by application of a newly-developed $\mathrm{Cu} / \mathrm{AlN}$ nano-multilayered coating. The nano-confinement of $\mathrm{Cu}$ is abrogated after brazing and, consequently, the brazed joints can be operated well above their reduced brazing temperatures. Nanostructured brazing fillers can principally be produced both in the form of coatings and free-standing brazing foils.

\section{Acknowledgments}

The authors gratefully acknowledge the support from the following persons: Joanna Lipecka, Ahmed Elrefaei and Ivan Shorubalko (Empa), Csaba Szendy (Institute of Materials Engineering, Technical University of Dortmund), Christian Küchenmeister (Intelligent Microsystems Institute, Technical University of Dortmund).

\section{REFERENCES}

1) P. Pawlow: Z. Phys. Chem. Stöchiom. Verwandsch. Lehre 1 (1909) 545.

2) M. Takagi: J. Phys. Soc. Japan 9 (1954) 359-363.

3) G. L. Allen, R. A. Bayles, W. W. Gile and W. A. Jesser: Thin Solid Films 144 (1986) 297-308.

4) Q. S. Mei and K. Lu: Prog. Mater. Sci. 52 (2007) 1175-1262.

5) J. Janczak-Rusch, G. Kaptay and L. P. H. Jeurgens: J. Mater. Eng. Perform. 23 (2014) 1608-1613.

6) J. Janczak-Rusch, G. Pigozzi, B. Lehmert, M. Parlinska, V. Bissig, W. Tillmann, L. Wojarski and F. Hoffmann: Proc. IBSC 2012 - 5th Int. Brazing and Soldering Conference 162 (2012) pp. 163-168.

7) L. P. H. Jeurgens, Z. M. Wang and E. J. Mittemeijer: Int. J. Mater. Res. 100 (2009) 1281-1307.

8) A. Novikov and M. Nowottnick: Phys. Status Solidi A 209 (2012) 819824.

9) A. Hu, J. Y. Guo, Y. Zhou, H. Alarifi, G. Patane, G. Compagnini and C. X. Xu: Appl. Phys. Lett. 97 (2010) 153117.

10) P. Peng, A. Hu, H. Huang, A. P. Gerlich, B. Zhao and Y. N. Zhou: J. Mater. Chem. 22 (2012) 12997-13001. 